(RESEARCH ARTICLE)

\title{
Establishment of local geometric geoid model for Busoga, Uganda
}

\author{
Bruno Kyamulesire ${ }^{1,}{ }^{*}$, Sylvester Okiemute Eteje ${ }^{2}$ and Paul Dare Oluyori ${ }^{3}$ \\ ${ }^{1}$ Associated Mapping Professionals, P. O. Box 5309, Jinja, Uganda. \\ 2 Eteje Surveys and Associates, Benin City, Edo State, Nigeria. \\ ${ }^{3}$ P. D. Horvent Surveys Ltd, FCT, Abuja, Nigeria.
}

Publication history: Received on 01 December 2020; revised on 09 December 2020; accepted on 11 December 2020

Article DOI: https://doi.org/10.30574/wjarr.2020.8.3.0468

\begin{abstract}
The importance of the local geoid model for the computation of accurate geoid heights, as well as orthometric heights used for engineering constructions, necessitated its establishment in areas, regions or countries. Consequently, this study establishes the local geometric geoid model of Busoga, Uganda, using the geometric method. A total of 26 points were used in the study, 20 points for the development of the model and 6 test points. GNSS observations were acquired with Trimble GNSS dual-frequency receivers and processed with Bernese (V5.2) and Spectra Precision Survey Office (v4.1) software to obtain the coordinates and ellipsoidal heights of the points. Differences between the existing orthometric and ellipsoidal heights were computed to obtain the geoid heights. The Least squares adjustment technique was applied to determine the fit, as well as the Bicubic and Multiquadratic models' parameters. The Root Mean Squares Error (RMSE) index was used to compute the accuracy of the models. The geoid models were compared with their RMSE, as well as accuracy to determine which of them is more suitable for application in the study area. The comparison result shows that the Multiquadratic geoid model is more suitable for implementation in the study area. A Microsoft Excel program was developed for the application of the model in the study area.
\end{abstract}

Keywords: Geoid; Orthometric; Undulation; Ellipsoidal; Height; Local; Model; Geometric

\section{Introduction}

The geoid is a surface adopted as a reference for practical, as well as orthometric heights computation. According to Jalal et al. [1], the geoid is a level surface, which is defined as a closed equigeopotential surface of the Earth's gravity nearest to the Mean Sea Level (MSL). The determination of the local geoid models of areas and regions has become crucial as the global geopotential models such as EGM 08, EGM 96, EGM 84 and EIGEN 6C4 do not best fit areas and regions. Also, the Global Navigation Satellite System (GNSS) ellipsoidal, as well as theoretical heights are not suitable for engineering construction as are computed on a specified ellipsoid which is not a level surface. By applying the ellipsoidal heights in an area, water cannot flow from one point to the other. But with orthometric heights, water can flow from one point to another.

The GNSS has the capability of determining the 3-D coordinates of points on the earth surface. The height component is theoretical. It is not a practical height obtained relative to the geoid. Orthometric height is obtained relative to the geoid using a level by spirit levelling. The process is laborious, costly and time-consuming. By applying it in a large area may result in significant errors in the observations; thereby reduce the resolution of the obtained heights. The ellipsoidal heights of points are converted to orthometric heights if their geoid heights are known. According to Mårtensson [2], obtaining orthometric heights this way, could in certain circumstances, depending on the required accuracy, replace conventional spirit levelling and thus make the levelling procedure cheaper and faster. Geoid heights are vertical

\footnotetext{
* Corresponding author: Bruno Kyamulesire

Associated Mapping Professionals, P. O. Box 5309, Jinja, Uganda.

Copyright (C) 2020 Author(s) retain the copyright of this article. This article is published under the terms of the Creative Commons Attribution Liscense 4.0.
} 
distances between the ellipsoid and the geoid. It is called geoid undulation, as well as geoid-ellipsoid separation. Figure 1 shows the relationship among the geoid, ellipsoidal and orthometric heights.

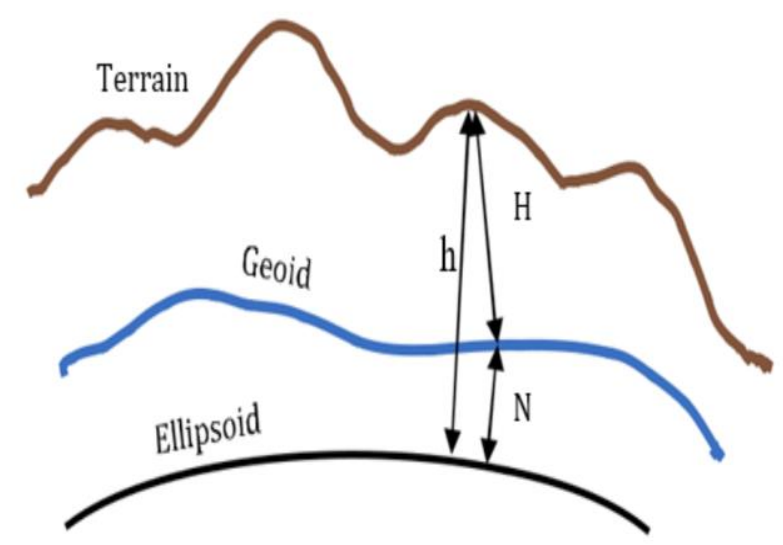

Figure 1 Relationship among the Geoid, Ellipsoidal and Orthometric Heights.

Source: Hasan and Ismat [3]

From Figure 1, orthometric heights can be computed if the ellipsoidal and the geoid heights are known using [4]

$H=h-N$

Where,

$\mathrm{H}=$ Orthometric height

$\mathrm{h}=$ Ellipsoidal height

$\mathrm{N}=$ Geoid height

The geometric method has been applied by various researchers in various parts of the world with different accuracy achieved. Jürgenson et al. [5] fitted a gravimetric geoid surface to existing geometric geoid heights in Estonian with an accuracy of 1.3cm; El-Hallaq [6] developed a local GPS-Levelling (geometric) geoid model for Gaza Strip Area and obtained an accuracy of $4.28 \mathrm{~cm}$. Tata and Ono [4] also applied the geometric method in Akure environs, Nigeria and achieved RMSE of $0.511 \mathrm{~m}$. Ismail et al. [7] established a new fitted geoid model in Universiti Teknologi Malaysia with an accuracy of $8 \mathrm{~mm}$. Das et al. [8] determined the local geoid model of Papua New Guinea by comparing three polynomial surfaces (second, third and fourth degree polynomial surfaces) and recommended the third degree polynomial surface with an accuracy of $\pm 20 \mathrm{~cm}$ for application in the study area. Oluyori et al. [9] compared two polynomial geoid models (Model 1 and Model 2) for orthometric heights interpolation in FCT, Abuja, Nigeria and recommends Model 1 with an accuracy of $11 \mathrm{~cm}$ for application in the study area. Kyamulesire et al. [10] also determined the local geoid model of Kampala, Uganda by comparing three plane geometric geoid surfaces (Model 1, Model 2 and Model 3) and recommended the three models for application in the study area with more reliability, as well as greater confidence in model 2.

The European Improved Gravity model of the Earth by New techniques, EIGEN-6C4 $[11,10]$ is a global geopotential model adopted for the conversion of ellipsoidal heights to orthometric heights in Uganda. It is well known that global geoid models best the entire globe but not areas, regions or countries. Their application in areas, regions or countries, yields very low accuracy. A truncated model at a lower spherical harmonic degree was applied in Jinja, Uganda, an accuracy of $1.390 \mathrm{~m}$ achieved is considered very low. Considering the low resolution of the global geoid model in the country, the local geoid model of Kampala which is the capital city of Uganda was determined using the geometric method [10]. Busoga is a sub-region of Uganda. It is a developing area that requires accurately obtained orthometric heights for the fast execution of infrastructural and civil engineering development programs such as highways, water flow, and in general, topographical base or working plans preparation. Consequently, this study establishes the local geoid model of Busoga, Uganda, using the geometric method. 


\subsection{The Study Areas}

The study area is Busoga, Uganda. According to Isiko [12], Busoga sub-region is located in the eastern part of Uganda, curved by Lake Kyoga in the north. Victoria Nile in the west separates Busoga from Buganda. In the south, Lake Victoria acts as the boundary that separates Busoga from the islands that belong to the Basamia and Buganda. Mpologoma River in the east separates Busoga from the districts that make up the former Bukedi region. The area covered by Busoga is about 8920 square kilometres, it is relatively flat. Busoga region lies between the equator and $2^{\circ} 00^{\prime \prime} \mathrm{N}$ and longitudes $33^{\circ} 00^{\prime \prime} \mathrm{E}$ and $34^{\circ} 00^{\prime \prime} \mathrm{E}$, the altitude above sea level varies between 1036.32 and 1219.20 metres [13]. Figure 2 shows the map of Uganda sub-regions.

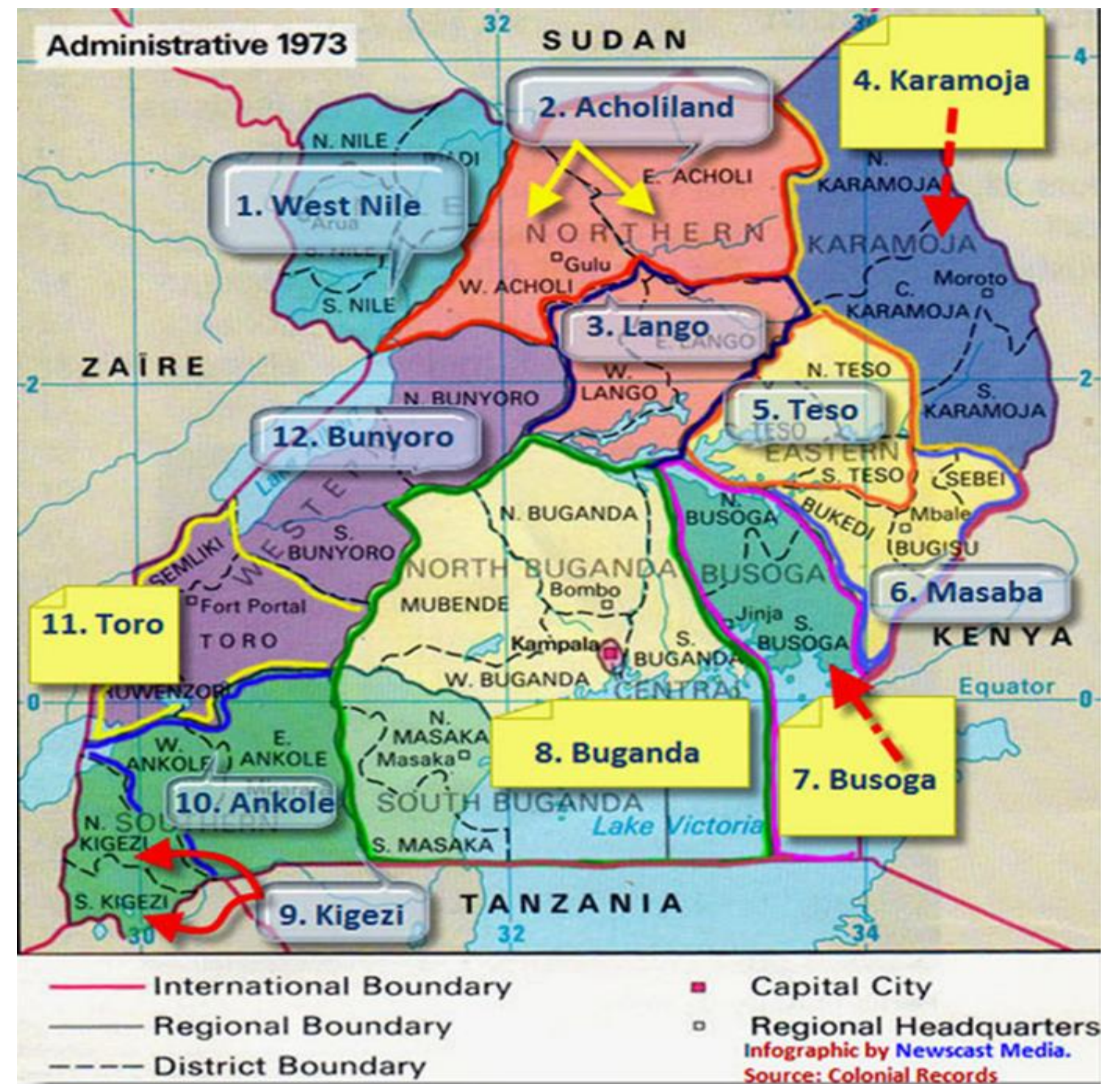

Figure 2 Map of Uganda Sub-Regions Showing Busoga

\subsection{Geometric Geoid Surfaces}

Geometric geoid surfaces are mathematical interpolation surfaces fitted to geoid heights to enable geoid heights of new points to be determined using variable such as geographic or rectangular coordinates. These surfaces include plane surface, bi-linear surface, second degree surface, third degree polynomial and fifth degree polynomial. The surface to be adopted, as well as the degree and order of the polynomial, depends on the size of the study area and variation of the geoid heights. For a small area; the plane surface is used, for a relatively large area; the second and third-order polynomial surfaces are used $[14,15]$. 
The study area (Busoga) is relatively large; as a result, the Bicubic and Multiquadratic model surfaces were applied in the study. The Bicubic model is a third degree polynomial surface used for geometric geoid modelling. The Bicubic geoid model as given in Kirici and Sisman [16] and Oduyebo et al. [15] is

$$
N=a_{0}+a_{1} X+a_{2} Y+a_{3} X^{2}+a_{4} X Y+a_{5} Y^{2}+a_{6} X^{3}+a_{7} X^{2} Y+a_{8} X Y^{2}+a_{9} Y^{3}
$$

Also, the Multiquadratic model given by Sanlioglu et al. [17] is

$$
N=a_{0}+a_{1} X+a_{2} Y+a_{3} X^{2}+a_{4} Y^{2}+a_{5} X Y+a_{6} X^{2} Y+a_{7} X Y^{2}+a_{8} X^{2} Y^{2}
$$

Where,

$Y=$ Northing, coordinate of observed station

$X$ = Easting, coordinate of observed station

$a_{0}, a_{1}, a_{2}, \ldots a_{n}=$ Model coefficient $/$ parameters

$\mathrm{N}=$ Geoid height

\subsection{Observation Equation Method of Least Squares Adjustment}

The fitting of the polynomial interpolation surface to a set of geoid heights requires the model parameters (variable coefficients) to be computed. The computation of these coefficients is done by observation equation method of least squares adjustment technique. The functional relationship between adjusted observations and the adjusted parameters as given by Eteje and Oduyebo [18] is

$$
L_{a}=F\left(X_{a}\right)
$$

Where, $L_{a}=$ adjusted observations and $X_{a}=$ adjusted parameters. Equation (4) is a linear function from which the general observation equation model was obtained. The system of observation equations is presented by matrix notation as [19]

$$
V=A X-L
$$

Where,

$$
\begin{aligned}
& A=\text { Design Matrix } \\
& X=\text { Vector of Unknowns } \\
& L=\text { Observation Matrix. } \\
& V=\text { Residual Matrix }
\end{aligned}
$$

The residual (V) is the difference between the estimate and the observed value. It is useful when applying the least squares adjustment technique in the computation of geoid model parameters. Since it is equal to the difference between the model geoid heights and the computed geoid heights from GNSS observations and spirit levelling, it is useful as a check. The model used for the computation of the unknown parameter as given in Oluyori et al. [20] is

$$
X=\left(A^{T} A\right)^{-1} A^{T} L
$$

Where,

$\left(A^{T} A\right)^{-1}=$ Inverse of the normal matrix 
The step by step procedures for the computation of the polynomial interpolation model Coefficients $\left(a_{m n}\right)$ of the variables $(\mathrm{x}, \mathrm{y})$ are detailed in Eteje and Oduyebo [18].

\subsection{Accuracy of the Model}

The accuracy of geometric geoid model is obtained using the Root Mean Square Error, RMSE index. To compute the accuracy of the model, the model geoid heights of the test points are compared with their corresponding computed geoid heights to obtain the geoid height residuals. The computed geoid heights are obtained by finding the differences between the known/existing orthometric heights and the GNSS ellipsoidal heights. The geoid height residuals and the total number of the test points are used to compute the RMSE, as well as the accuracy of the model. Here, the accuracy of the model varies inversely to the computed value of the RMSE [21]. The Root Mean Square Error, RMSE index used for the computation of the geometric geoid model accuracy as given by Yilmaz and Kozlu [22] is

$$
R M S E= \pm \sqrt{\frac{1}{n} \sum_{i=1}^{n}\left(\delta N_{\text {Residual }}\right)^{2}}
$$

Where,

$$
\begin{aligned}
& \delta N_{\text {Residual }}=\left(N_{\text {Computed }}-N_{\text {Model }}\right) \\
& N_{\text {Computed }}=\text { Geoid height from existing orthometric and GNSS ellipsoidal heights } \\
& N_{\text {Model }}=\text { Geometric Geoid Height } \\
& \mathrm{n}=\text { Number of Points }
\end{aligned}
$$

\section{Methodology}

\subsection{Data Acquisition}

A total of 26 points were used in the study, 20 points for modelling the local geoid and 6 test points. The orthometric heights have previously determined by gravimetric means [23]. GNSS observation was carried out with Trimble GNSS dual-frequency Receivers in static mode to obtain the coordinates and ellipsoidal heights of the points. The occupation period of each point during the observation was 3 hours. It was carried out from 27th February, 2019 to 22nd April, 2019. Figure 3 shows the GNSS receiver at station U2092.

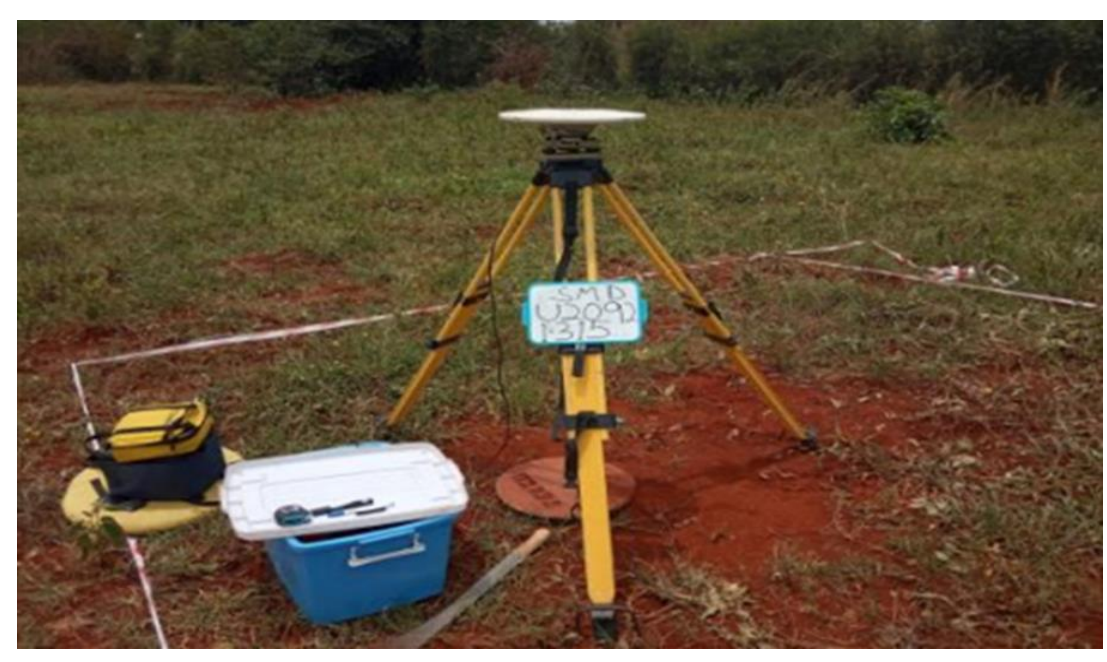

Figure 3 GNSS Receiver at Station U2092

\subsection{Data Processing}

The GNSS observations were processed using Bernese (V5.2) and Spectra Precision Survey Office (v4.1) software in ITRF2005 (Epoch 2010.0) datum (UTM zone 36N). The geoid heights of the points were computed by subtracting the existing orthometric heights from their corresponding ellipsoidal heights obtained from the processed GNSS 
observations using equation (1). Table 1 shows the GNSS ellipsoidal heights, existing orthometric heights and the computed geoid heights.

Table 1 Ellipsoidal, Existing Orthometric and Computed Geoid Heights

\begin{tabular}{|l|l|l|l|}
\hline Station & $\begin{array}{l}\text { GNSS Ellipsoidal } \\
\text { Height (m) }\end{array}$ & $\begin{array}{l}\text { Existing Orthometric } \\
\text { Height (m) }\end{array}$ & $\begin{array}{l}\text { Computed Geoid } \\
\text { Height (m) }\end{array}$ \\
\hline U2022 & 1158.850 & 1172.250 & -13.400 \\
\hline U1068 & 1044.100 & 1058.240 & -14.140 \\
\hline U1057 & 1086.010 & 1100.350 & -14.340 \\
\hline U1033 & 1181.940 & 1197.050 & -15.110 \\
\hline U2113 & 1086.570 & 1101.140 & -14.570 \\
\hline U2112 & 1097.770 & 1112.350 & -14.580 \\
\hline U2110 & 1125.030 & 1139.270 & -14.240 \\
\hline U2109 & 1104.950 & 1119.250 & -14.300 \\
\hline U2108 & 1092.070 & 1106.750 & -14.680 \\
\hline U2107 & 1123.340 & 1138.090 & -14.750 \\
\hline U2094 & 1190.660 & 1205.870 & -15.210 \\
\hline U2092 & 1167.760 & 1182.900 & -15.140 \\
\hline U2027 & 1064.240 & 1077.550 & -13.310 \\
\hline U2025 & 1186.120 & 1199.240 & -13.120 \\
\hline U2024 & 1179.020 & 1192.240 & -13.220 \\
\hline U2023 & 1173.210 & 1186.640 & -13.430 \\
\hline U1060 & 1093.550 & 1107.100 & -13.550 \\
\hline U1023 & 1133.060 & 1148.360 & -15.300 \\
\hline U1031 & 1136.210 & 1150.940 & -14.730 \\
\hline U1039 & 1168.900 & 1183.260 & -14.360 \\
\hline
\end{tabular}

The Bicubic and Multiquadratic models' (equations (2) and (3) respectively) parameters were computed with the coordinates and geoid heights of the points using the least squares technique, as well as equation (6). The computations were done with Microsoft Excel programs. The fit, as well as the models' parameters, is necessary to enable the interpolation of geoid heights of new points in the study area using their (the points') coordinates. The parameters were substituted accordingly into their respective equations, and Microsoft Excel programs developed for the implementation of the models in the study area. The computed Bicubic and Multiquadratic models' parameters are respectively.

Bicubic Model Parameters

$$
\left(\begin{array}{l}
a_{0} \\
a_{1} \\
a_{2} \\
a_{3} \\
a_{4} \\
a_{5} \\
a_{5} \\
a_{7} \\
a_{8} \\
a_{9}
\end{array}\right)=\left(\begin{array}{c}
240.76341902464600000000 \\
-0.00114399719409874000 \\
-0.00085059990196612000 \\
0.00000000166805702946 \\
-0.00000000080588327770 \\
0.00000000322991026934 \\
-0.00000000000000294646 \\
0.00000000000000086501 \\
-0.00000000000000078983 \\
0.00000000000000086910
\end{array}\right)
$$

\section{Multiquadratic Model Parameters}

$\left(\begin{array}{l}a_{0} \\ a_{1} \\ a_{2} \\ a_{3} \\ a_{4} \\ a_{5} \\ a_{6} \\ a_{7} \\ a_{8}\end{array}\right)=\left(\begin{array}{c}102.85633611679000000000 \\ -0.00039790502501091400 \\ -0.00052147435781080300 \\ 0.00000000033379623013 \\ -0.00000000465848035147 \\ 0.00000000186211076073 \\ -0.00000000000000158772 \\ 0.00000000000001656664 \\ -0.00000000000000000002\end{array}\right)$


The accuracy of the models were computed with the 6 test points' existing orthometric heights and the GNSS ellipsoidal heights. The geoid heights of the points were computed by finding the differences between the ellipsoidal heights and the orthometric heights. The computed geoid heights were compared with their respective geoid heights from the two models to obtain the residuals. The accuracy computation was done using the RMSE index, as well as equation (7).

\section{Results}

Table 2 presents the computed geoid heights, Bicubic and Multiquadratic models' geoid heights and the averages of the absolute differences between the computed and the two models' geoid heights. It was done to present the minimum and maximum geoid heights of the two models and the averages of their absolute differences between the computed geoid heights.

Table 2 Computed, Bicubic, Multiquadratic Geoid Heights and their Absolute Differences

\begin{tabular}{|c|c|c|c|c|c|}
\hline Station & $\begin{array}{l}\text { Computed } \\
\text { Geoid Height } \\
\text { (m) (A) }\end{array}$ & $\begin{array}{ll}\text { Bicubic } & \text { Model } \\
\text { Geoid } & \text { Height } \\
\text { (m) (B) } & \end{array}$ & $\begin{array}{l}\text { Multiquadratic } \\
\text { Model Geoid } \\
\text { Height (m) (C) }\end{array}$ & $\begin{array}{l}I(A)-(B) I \\
(m)\end{array}$ & $\begin{array}{l}\mathrm{I}(\mathrm{A})-(\mathrm{C}) \mathrm{I} \\
(\mathrm{m})\end{array}$ \\
\hline U2022 & -13.400 & -13.407 & -13.403 & 0.007 & 0.003 \\
\hline U1068 & -14.140 & -14.170 & -14.179 & 0.030 & 0.039 \\
\hline U1057 & -14.340 & -14.331 & -14.316 & 0.009 & 0.024 \\
\hline U1033 & -15.110 & -15.072 & -15.063 & 0.038 & 0.047 \\
\hline U2113 & -14.570 & -14.516 & -14.520 & 0.054 & 0.050 \\
\hline U2112 & -14.580 & -14.531 & -14.534 & 0.049 & 0.046 \\
\hline U2110 & -14.240 & -14.241 & -14.242 & 0.001 & 0.002 \\
\hline U2109 & -14.300 & -14.310 & -14.309 & 0.010 & 0.009 \\
\hline U2108 & -14.680 & -14.749 & -14.754 & 0.069 & 0.074 \\
\hline U2107 & -14.750 & -14.860 & -14.860 & 0.110 & 0.110 \\
\hline U2094 & -15.210 & -15.128 & -15.120 & 0.082 & 0.090 \\
\hline U2092 & -15.140 & -15.111 & -15.128 & 0.029 & 0.012 \\
\hline U2027 & -13.310 & -13.386 & -13.373 & 0.076 & 0.063 \\
\hline U2025 & -13.120 & -13.064 & -13.077 & 0.056 & 0.043 \\
\hline U2024 & -13.220 & -13.224 & -13.230 & 0.004 & 0.010 \\
\hline U2023 & -13.430 & -13.466 & -13.464 & 0.036 & 0.034 \\
\hline U1060 & -13.550 & -13.517 & -13.512 & 0.033 & 0.038 \\
\hline U1023 & -15.300 & -15.386 & -15.388 & 0.086 & 0.088 \\
\hline U1031 & -14.730 & -14.666 & -14.652 & 0.064 & 0.078 \\
\hline \multirow[t]{2}{*}{ U1039 } & -14.360 & -14.343 & -14.356 & 0.017 & 0.004 \\
\hline & & & Average $=$ & 0.043 & 0.043 \\
\hline
\end{tabular}

Figures 4 to 6 and Figure 7 respectively present the contour and linear plots of the computed, Bicubic and Multiquadratic geoid heights of the points. They were plotted to show graphically, the shapes and agreements of the Bicubic and the Multiquadratic models' geoid heights with the computed geoid heights. 


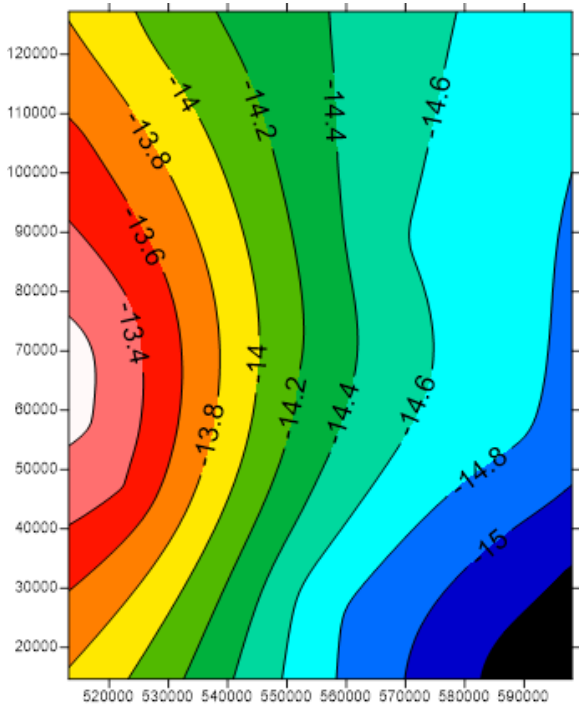

Figure 4 Computed Geoid Heights Contour Plot

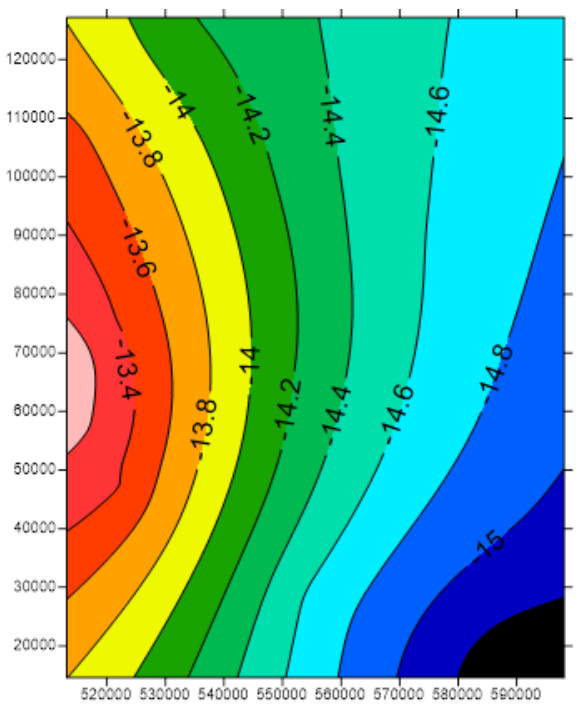

Figure 5 Bicubic Model Geoid Heights Contour Plot

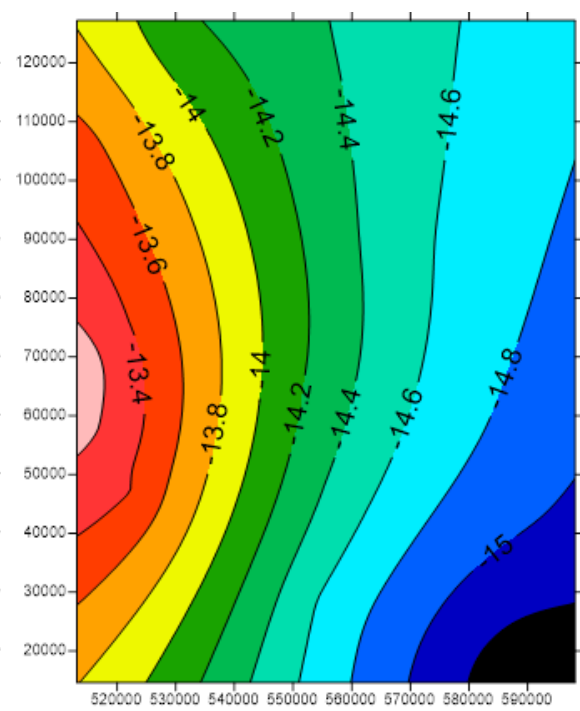

Figure 6 Multiquadratic Model Geoid Heights Contour Plot

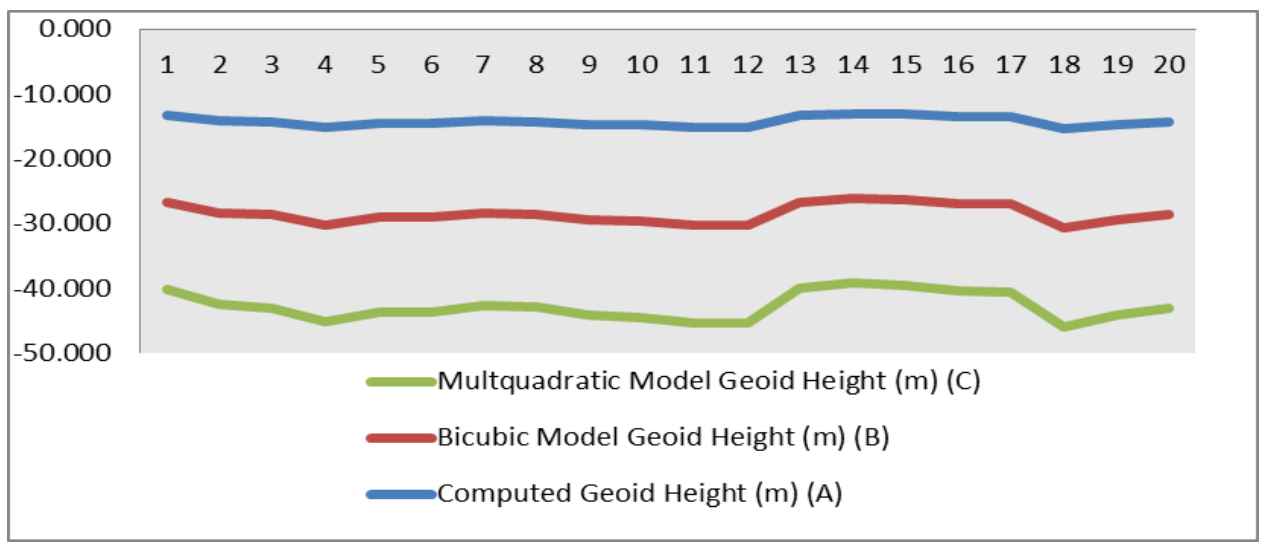

Figure 7 Plots of Computed, Bicubic and Multiquadratic Geoid Heights

Table 3 presents the Root Mean Square Errors (RMSEs) of the Bicubic and Multiquadratic geoid models using the 6 test points. The RMSEs were computed to show and compare the accuracy of the two models to determine which of them (the models) is more suitable for use in the study area.

Table 3 Bicubic and Multiquadratic Models' RMSE Computation Using the Test Points

\begin{tabular}{|c|c|c|c|c|}
\hline $\begin{array}{l}\text { Computed } N \\
\text { (m) (P) }\end{array}$ & $\begin{array}{l}\text { Bicubic N (m) } \\
\text { (Q) }\end{array}$ & $\begin{array}{l}\text { Multiquadratic } \\
\text { N (m) (S) }\end{array}$ & $\begin{array}{l}((P)-(Q))^{2} \\
\text { Bicubic }\end{array}$ & $\begin{array}{l}((\mathrm{P})-(\mathrm{S}))^{2} \\
\text { Multiquadratic }\end{array}$ \\
\hline-14.200 & -14.212 & -14.207 & 0.000133 & 0.000054 \\
\hline-14.660 & -14.768 & -14.775 & 0.011688 & 0.013194 \\
\hline-14.520 & -14.495 & -14.495 & 0.000618 & 0.000629 \\
\hline-15.170 & -15.107 & -15.108 & 0.004011 & 0.003825 \\
\hline-13.250 & -13.269 & -13.266 & 0.000376 & 0.000264 \\
\hline \multirow[t]{2}{*}{-13.740} & -13.871 & -13.833 & 0.017162 & 0.008668 \\
\hline & & $\operatorname{RMSE}(\mathrm{m})=$ & 0.075264 & 0.066625 \\
\hline
\end{tabular}




\section{Discussion}

In Table 2, the minimum and maximum geoid heights of the Bicubic and Multiquadratic geoid models are respectively $15.386 \mathrm{~m}$ and $-13.064 \mathrm{~m}$, and $-15.388 \mathrm{~m}$ and $-13.077 \mathrm{~m}$. It shows that geoid heights can be respectively interpolated in the study area with the Bicubic and Multiquadratic models within the ranges of $-15.386 \mathrm{~m}$ to $-13.064 \mathrm{~m}$, and $-15.388 \mathrm{~m}$ to $13.077 \mathrm{~m}$. Also, in Table 2, the averages of the absolute differences between the computed geoid heights and the two models geoid heights are $0.043 \mathrm{~m}$. It implies a good fit of the two geoid surfaces to the computed geoid heights.

In Figures 4 to 6, the shapes of the two geoid models' contour maps are identical with that of the computed geoid heights. It shows the agreement of the two geoid models' geoid heights with the computed geoid heights of the study area. Also, in Figure 7, the linear plots of the Bicubic and Multiquadratic models' geoid heights are identical with that of the computed geoid heights. It also indicates the agreement, as well as a good fit of the two geoid surfaces to the computed geoid heights.

It can again be seen in Table 3 that the RMSEs of the Bicubic and Multiquadratic geoid models are respectively $0.075 \mathrm{~m}$ and $0.067 \mathrm{~m}$. According to Oluyori and Eteje (2020), the accuracy of the model varies inversely to the computed value of the RMSE. It implies that the Multiquadratic geoid model is more suitable for application in the study area. It also shows that geoid heights can be interpolated in the study area with an accuracy of $0.067 \mathrm{~m}$ with the Multiquadratic geoid model. The accuracy achieved in this study is within the ones obtained in previous studies [4-10]. With an accuracy of less than $10 \mathrm{~cm}$ for the recommended model, it is fit for applications like engineering feasibility studies, GIS topographic mapping, remote sensing land-cover mapping projects and oceanographic applications [24].

\section{Conclusion}

In conclusion, the study has established the local geoid model of Busoga, Uganda, using the geometric method. It has shown that the Multiquadratic geoid model is more suitable for application in the study area. It has also revealed that geoid heights can be interpolated in the study area with an accuracy of $0.067 \mathrm{~m}$ using the recommended geoid model. The study has developed a Microsoft Excel program for implementation of the determined geoid model in the study area.

\section{Compliance with ethical standards}

\section{Acknowledgments}

The authors would like to appreciate the commissioner of Department of Survey and Mapping, Mr. Ogaro Wilson and the Project Manager of UGRF, Mr. Lutaaya John for providing reports on how the observations were acquired and processed for the passive points.

\section{Disclosure of conflict of interest}

The authors declare that there is no conflict of interest in this study

\section{References}

[1] Jalal SJ, Musa TA, Din AH, Aris WAW, Shen W, Pa'suya MF. Influencing Factors on the Accuracy of Local Geoid Model. Geodesy and Geodynamics. 2019; 8: 439-445.

[2] Mårtensson S. Height Determination by GPS -Accuracy with Respect to Different Geoid Models in Sweden. FIG XXII International Congress, Washington, D.C. USA. 2002.

[3] Hasan B, Ismat A. Geoid Modelling for Surveying Works Using Satellite Geo-Spatial Data. Civil Engineering Research Journal. 2020; 10(2): 25-27.

[4] Tata H, Ono M N. A Geometric Approach for Determination of Geoidal Height in Akure Environs, Ondo State, Nigeria. International Journal of Scientific and Research Publications. 2018; 8(8): 668-677.

[5] Jürgenson H, Türk K, Randjärv J. Determination and Evaluation of the Estonian Fitted Geoid Model EST-GEOID 2003. Geodesy and Cartography. 2011; 37(1): 15-21. 
[6] El-Hallaq MA. Development of a Local GPS-Leveling Geoid Model for the Gaza Strip Area. International Journal of Emerging Technology and Advanced Engineering. 2012; 2(1): 268-273.

[7] Ismail MK, Din AHM, Uti MN, Omar AH. Establishment of New Fitted Geoid Model in Universiti Teknologi Malaysia. The International Archives of the Photogrammetry, Remote Sensing and Spatial Information Sciences. 2018; 42: 27-33.

[8] Das RK, Samanta S, Jana KS, Rosa R. Polynomial Interpolation Methods in Development of Local Geoid Model. The Egyptian Journal of Remote Sensing and Space Sciences. 2018; 21: 265-271.

[9] Oluyori PD, Ono MN, Eteje So. Comparison of Two Polynomial Geoid Models of GNSS/Levelling Geoid Development for Orthometric Heights in FCT, Abuja. International Journal of Engineering Research and Advanced Technology (IJERAT). 2018; 4(10): 1-9.

[10] Kyamulesire B, Oluyori PD, Eteje SO. Comparative Analysis of Three Plane Geometric Geoid Surfaces for Orthometric Height Modelling in Kampala, Uganda. FUDMA Journal of Sciences (FJS). 2020; 4(3): 43-51.

[11] Kostelecký J, Klokocník J, Bucha B, Bezdek A, Förste C. Evaluation of the Gravity Field Model EIGEN-6C4 in Comparison with EGM2008 by Means of Various Functions of the Gravity Potential and by GNSS/Levelling. Geoinformatics FCE CTU. 2015; 14(1): 7-28.

[12] Isiko AP. Gender Roles in Traditional Healing Practices in Busoga. Published Ph.D. Dissertation, Leiden University. 2018.

[13] Innes JR. Leprosy in Uganda: A survey in the Busoga District of the Eastern Province. International Journal of Leprosy. 1950; 507-517.

[14] Eteje SO, Oduyebo OF, Olulade SA. Procedure for the Determination of Local Gravimetric-Geometric Geoid Model. International Journal of Advances in Scientific Research and Engineering. 2018; 4(8): 206-214.

[15] Oduyebo OF, Ono MN, Eteje SO. Comparison of Three Gravimetric-Geometric Geoid Models for Best Local Geoid Model of Benin City, Nigeria. International Journal of Advanced Engineering Research and Science (IJAERS). 2019; 6(12): 261-272.

[16] Kirici U, Sisman Y. The Comparison of the Adjustment Methods in Geoid Determination Method. FIG Working Week, Helsinki, Finland. 2017.

[17] Sanlioglu I, Maras SS, Uysal F. Determination of Orthometric Heights with Real-Time Kinematic Surveying, Konya Sample, FIG Working Week. 2009.

[18] Eteje SO, Oduyebo FO. Local Geometric Geoid Models Parameters and Accuracy Determination Using Least Squares Technique. International Journal of Innovative Research and Development (IJIRD). 2018; 7(7): $251-257$.

[19] Ono MN, Eteje SO Oduyebo FO. Comparative Analysis of DGPS and Total Station Accuracies for Static Deformation Monitoring of Engineering Structures. IOSR Journal of Environmental Science, Toxicology and Food Technology (IOSR-JESTFT). 2018; 12(6): 19-29.

[20] Oluyori PD, Ono MN, Eteje SO. Modelling of Orthometric heights from Multi-Networks of GNSS/Precise Levelling in FCT, Abuja. International Journal of Environment, Agriculture and Biotechnology (IJEAB). 2019; 4(4): 11811194.

[21] Oluyori PD, Eteje SO. The Implication of Significant Number in Geodetic Computations: Geometric Geoid Model of FCT Abuja as a Case Study. International Journal of Scientific and Technological Research. 2020; 6(8): 84-91.

[22] Yilmaz M, Kozlu B. The Comparison of Gravity Anomalies based on Recent High-Degree Global Models. Afyon Kocatepe University Journal of Science and Engineering. 2018; 18: 981-990.

[23] MLHUD. Updating and Implementing of Geodetic Reference Frame for Land Administration in Uganda: Computation of the Network of First and Second Order. Ministry of Land, Housing and Urban Development Technical Report. 2019.

[24] Kenduiywo BK, Odera PA, Waithaka EH. Orthometeric Height Determination Using GPS to Fast Track Development: A case study of Nairobi County, Kenya. Proceedings of Global Geospatial Conference, Addis Ababa, Ethiopia. 2013. 